ARTICLE

\title{
Assessment of Doses from External Exposure in Contaminated Areas Resulting from the Fukushima Daiichi Nuclear Power Plant Accident
}

\author{
Shogo TAKAHARA ${ }^{1 *}$, Masanori KIMURA ${ }^{1}$, Sakae KINASE ${ }^{1}$, Jun ISHIKAWA ${ }^{1}$, \\ Kenya SUYAMA ${ }^{1}$, Ryuji HOSOYAMADA ${ }^{1}$ and Toshimitsu HOMMA ${ }^{1}$ \\ ${ }^{I}$ Nuclear Safety Research Center, Japan Atomic Energy Agency
}

\begin{abstract}
The Fukushima Daiichi Nuclear Power Plant accident caused a release of radioactive material into the atmosphere and subsequent radioactive contamination of the environment. In the present study, doses from external exposure due to the deposited radionuclides were assessed based on compositions of the released radionuclides taking into account short-lived and long-lived ones. The assessment was performed on the assumption that dose rates would decrease with the radioactive decay as well as weathering effects. The compositions of released radionuclides were evaluated by source terms analysis which consisted in evaluating the released fractions to the initial inventories in the reactor core. As a result, it was confirmed that the doses evaluated in the present study were in good agreement with the measured ones in the northwest area from the nuclear power plant. In addition, it was found that ${ }^{132} \mathrm{Te}$ and its progeny nuclide, ${ }^{132} \mathrm{I}$, were dominant contributors to cumulative doses in the early phase after the accident. Following the decay of these short-lived radionuclides, long-lived ${ }^{134} \mathrm{Cs}$ and ${ }^{137} \mathrm{Cs}$ were the dominant ones.
\end{abstract}

\section{KEYWORDS: Fukushima Daiichi nuclear power plant accident, Dose Assessment, source ter msanalysis, short-lived radionuclides}

\section{Introduction}

The accident at the Fukushima Daiichi Nuclear Power Plant (NPP) caused the extensive radioactive contamination. In particular, the radioactive materials with high concentrations were observed in the northwest area from the NPP, which includes Namie town, Iitate village, Kawamata town, Fukushima city, etc.

Dose assessment is one of the most important processes to identify actions to be taken to reduce exposure in contaminated areas. Doses to inhabitants living in contaminated areas should be assessed retrospectively and prospectively taking into account contributions of short-lived and long-lived radionuclides from various exposure pathways. External exposure has occurred by cloudshine during radioactive plume passage and groundshine due to deposited radionuclides in the contaminated area after the accident ${ }^{1)}$.

In the present study were assessed external doses due to deposited radionuclides, which constitute one of the most important exposure pathways. The information on long-lived radionuclides deposited on the ground is available from environmental measurements. On the other hand, it is practically difficult to reflect the contributions of various short-lived radionuclides to the dose assessment. Therefore, in order to take the contributions of short-lived radionuclides into account in the dose assessment, the information of the released radioactivity was used. This information was obtained from an initial inventory in the reactor core evaluated and released fractions of the radionuclides into the atmosphere published.

*Corresponding Author, E-mail:takahara.shogo@jaea.go.jp

(C) 2012 Atomic Energy Society of Japan, All Rights Reserved.

\section{Methods}

1. The description of radioactive contamination in the northwest area of the Nuclear Power Plant

The radioactive contamination in the northwest area occurred on 15-16 March, 2011. During this period, two major incidents took place in the NPP. On 15 March, a blast sound from Unit 2 and a subsequent suppression pool pressure rapidly decreased. A few hours after this incident, an explosion occurred in the reactor building at Unit 4 where the spent fuel storage pool is located.

In the present study, because the short-lived radionuclides were detected in the contaminated area, dose assessment was performed on the assumption that the radioactive plume was released from Unit 2. The radioactive plume released from Unit 2 moved towards the northwest area and the contamination occurred as a result of the deposition of radioactive material from this plume.

The radioactive contamination levels of the environment in the northwest area were measured by a national authority and these measurements are available from the web site ${ }^{2}$. Ambient dose rates measured at Namie town, Kawamata town and Fukusima city were used in the present study. Locations of each sampling point are shown in Fig. 1. The distances from the NPP to each sampling point are approximately 20 to $60 \mathrm{~km}$.

\section{Released fractions and the inventory of the reactor core}

The report of Japanese Government to the IAEA Ministerial Conference on Nuclear Safety ${ }^{3)}$ indicates the fractions of radionuclides to the initial inventory released from Unit 2 for five accident scenarios obtained from the 


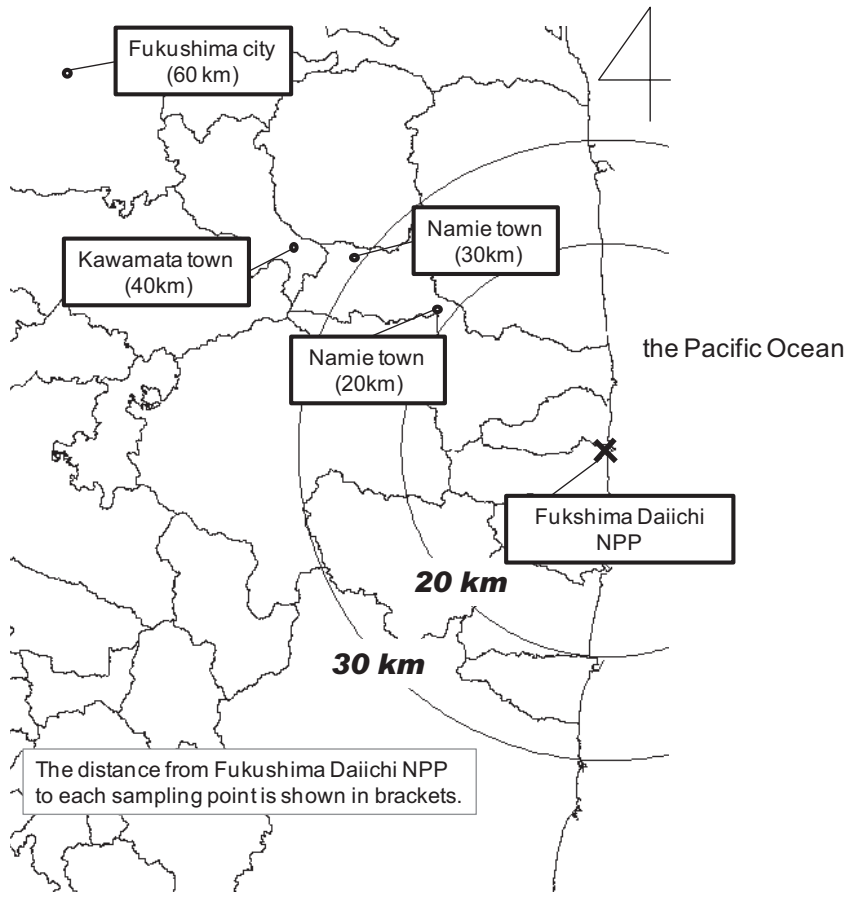

Fig. 1 Ambient dose rate sampling points used for the present

analyses by Tokyo Electric Power Company (TEPCO) and Japan Nuclear Energy Safety Organization (JNES). Table 1 shows the fractions of each radionuclide group to the initial inventory for the five accident scenarios.

The initial inventory in the reactor core of Unit 2 was evaluated based on the information on its operating history, number of fuel assemblies and burn-up of fuels. This information is available from the records of periodic inspections of Unit 2. Table 2 shows the information used for this evaluation. In calculating the inventories was used the ORIGEN2.2 $\mathrm{UPJ}^{4)}$ code, which is a computer code system for evaluating the buildup and the radioactive decay of approximately 1000 isotopes in the nuclear reactor core. A cross section data set $^{5)}$ based on JENDL-3.3 ${ }^{6}$ for BWR STEP-III fuel assembly was selected assuming the averaged void fraction of $40 \%$. Data of the radioactive decay constants, branching ratios and the fission yields were taken from the libraries based on JENDL FP decay Data File $2000^{7)}$ taking 44 radionuclides into account. Since the power history of each fuel assembly was not available, the average power history was assumed in the evaluation.

Generally, it is well known that the uranium having several initial ${ }^{235} \mathrm{U}$ enrichments is used in BWR fuel assembly. However, the inventories of the fission products mainly depend upon the fission yield of each nuclides and the number of fission reaction, i.e. burn-up. The representative value of $3.7 \mathrm{wt} \%$ of uranium enrichment was applied to the evaluation.

Table 2 The conditions of Unit 2 at the time of the accident

\begin{tabular}{ccc}
\hline $\begin{array}{c}\text { Electric } \\
\text { output }\end{array}$ & $\begin{array}{c}\text { Number of } \\
\text { fuel assemblies }\end{array}$ & $\begin{array}{c}\text { Average burn-up of } \\
\text { fuel assemblies }\end{array}$ \\
\hline $784 \mathrm{MWe}$ & 548 & $23 \mathrm{GWd} / \mathrm{t}$ \\
\hline
\end{tabular}

\section{Assessment of doses from external exposure due to deposited radioactive material}

The cumulative effective doses $E(T)$ to the public in $T$ days after the deposition of radionulclides on the ground is given as follows:

$$
E(T)=\int_{0}^{T}\left(D(t) \cdot F \cdot \sum_{\mathrm{j}} \mathrm{S}_{\mathrm{j}} \cdot B_{\mathrm{j}}\right) \mathrm{d} t
$$

where

$D(t)$ : Ambient dose rate in $t$ days after the deposition $(\mu \mathrm{Sv} / \mathrm{h})$;

$F \quad$ : Conversion coefficient from ambient dose rate to effective dose;

$S_{\mathrm{j}} \quad$ : Shielding factor at location $\mathrm{j}$;

$B_{\mathrm{j}} \quad$ : Occupancy factor at location $\mathrm{j}$.

In the present study, it was assumed that the irradiations have occurred in Antero-Posterior (AP) geometry, hence, 0.92 is adopted for the conversion coefficient $F^{8)}$. Shielding factor $S_{\mathrm{j}}$ is the ratio of the ambient doses at location $\mathrm{j}$ and at the outdoor for adults. The factor was used for indoor, $S_{\text {indoor }}$, of a typical house $0.4^{9)}$ and for outdoor, $S_{\text {outdoor }}$ of 1.0 . Occupancy factor is the fraction of time spent at location. On the assumption that the inhabitants would have spend 16 hours in a house and 8 hours outdoor, $B_{\text {indoor }}$ and $B_{\text {outdoor was }}$ $2 / 3$ and $1 / 3$, respectively.

Here, the ambient dose rate $t$ days after the deposition, $D_{\mathrm{i}}(t)$, is expressed by:

$$
D(t)=\sum_{\mathrm{i}} D_{\mathrm{i}}(t) .
$$

The ambient dose rate due to the deposited radionuclide $\mathrm{i}$ in $t$ days after the deposition is given by the following equation:

$$
D_{\mathrm{i}}(t)=D_{\mathrm{i}}(0) \cdot f \cdot \exp \left(-\lambda_{i} \cdot t\right)
$$

\begin{tabular}{|c|c|c|c|c|c|c|c|}
\hline \multicolumn{2}{|c|}{ Representative radionuclide } & $\mathrm{I}$ & $\mathrm{Cs}-\mathrm{Rb}$ & $\mathrm{Te}-\mathrm{Sb}$ & $\mathrm{Sr}-\mathrm{Ba}$ & $\mathrm{Ru}$ & $\mathrm{La}$ \\
\hline \multicolumn{2}{|c|}{ Radionuclide group } & 1 & 2 & 3 & 4 & 5 & 6 \\
\hline \multirow{5}{*}{$\begin{array}{l}\text { Accident } \\
\text { scenarios }\end{array}$} & TEPCO-1 ${ }^{*}$ & $3.80 \times 10^{-3}$ & $3.40 \times 10^{-3}$ & $4.20 \times 10^{-3}$ & $4.90 \times 10^{-4}$ & $7.60 \times 10^{-10}$ & $6.50 \times 10^{-8}$ \\
\hline & TEPCO- $2^{*}$ & $6.70 \times 10^{-2}$ & $5.80 \times 10^{-2}$ & $3.00 \times 10^{-2}$ & $2.60 \times 10^{-4}$ & $5.40 \times 10^{-10}$ & $8.40 \times 10^{-7}$ \\
\hline & Case- $1^{* *}$ & $1.30 \times 10^{-3}$ & $4.60 \times 10^{-4}$ & $2.50 \times 10^{-4}$ & $3.30 \times 10^{-4}$ & $2.00 \times 10^{-11}$ & $1.50 \times 10^{-9}$ \\
\hline & Case- $2^{* *}$ & $3.90 \times 10^{-2}$ & $3.80 \times 10^{-2}$ & $5.10 \times 10^{-2}$ & $2.90 \times 10^{-4}$ & $4.10 \times 10^{-11}$ & $1.10 \times 10^{-6}$ \\
\hline & Case- $-3^{* *}$ & $4.10 \times 10^{-2}$ & $3.90 \times 10^{-2}$ & $3.50 \times 10^{-2}$ & $4.00 \times 10^{-4}$ & $4.60 \times 10^{-11}$ & $1.20 \times 10^{-6}$ \\
\hline
\end{tabular}

Table 1 Release fractions of each radionuclide based on the source terms analyses ${ }^{3)}$

"evaluated by TEPCO, ${ }^{* *}$ evaluated by JNES 
where

$$
\begin{aligned}
& D_{\mathrm{i}}(0) \text { : Initial value of the ambient dose rate due to } \\
& \text { radionuclide } \mathrm{i}(\mu \mathrm{Sv} / \mathrm{h}) ; \\
& f \quad \begin{array}{l}
\text { : Reduction factor according to weathering } \\
\text { effects; }
\end{array} \\
& \lambda_{\mathrm{i}} \quad \text { : Decay constant for radionuclide } \mathrm{i}(1 / \mathrm{h}) .
\end{aligned}
$$

Here $D_{\mathrm{i}}(0)$ is calculated by:

$$
D_{\mathrm{i}}(0)=\frac{A_{\mathrm{i}}(0) \cdot D F_{\mathrm{i}}}{\sum_{\mathrm{i}} A_{\mathrm{i}}(0) \cdot D F_{\mathrm{i}}} \cdot D(0),
$$

where

$A_{\mathrm{i}}(0)$ : Initial value of the activity of deposited radionuclide $\mathrm{i}\left(\mathrm{Bq} / \mathrm{m}^{2}\right)$;

$D(0) \quad$ : Initial value of the ambient dose rate taken from measurement $(\mu \mathrm{Sv} / \mathrm{h})$;

$D F_{\mathrm{i}} \quad$ : Effective dose coefficient for exposure from the deposited radionuclide i $\left((\mu \mathrm{Sv} / \mathrm{h}) /\left(\mathrm{Bq} / \mathrm{m}^{2}\right)\right)$.

Effective dose coefficients were taken from U.S. EPA's work $^{10)}$.

The initial point of time $t$ is at 00:00 on 16 March and doses were assessed after this time. The initial dose rates, $D(0)$, were gained from the measured values of each sampling point at the initial time. The present study has been performed on the assumption that the transport phenomenon in the atmosphere do not depend upon radionuclides. Hence, the initial composition of the deposited radionuclides were determined by the composition of released radioactivities from the reactor core into the atmosphere.

The reduction factor according to weathering effects is assumed to be described as the two-exponential model which is proposed by Gale et al. ${ }^{11)}$ as the following equation:

$$
f=0.63 \cdot \exp \left(-\lambda_{\mathrm{w} 1} \cdot t\right)+0.37 \cdot \exp \left(-\lambda_{\mathrm{w} 2} \cdot t\right),
$$

where $\lambda_{w 1}$ and $\lambda_{w 2}$ are decay constants and their values are $1.30 \times 10^{-4} 1 / \mathrm{h}$ and $8.60 \times 10^{-7} 1 / \mathrm{h}$, respectively.

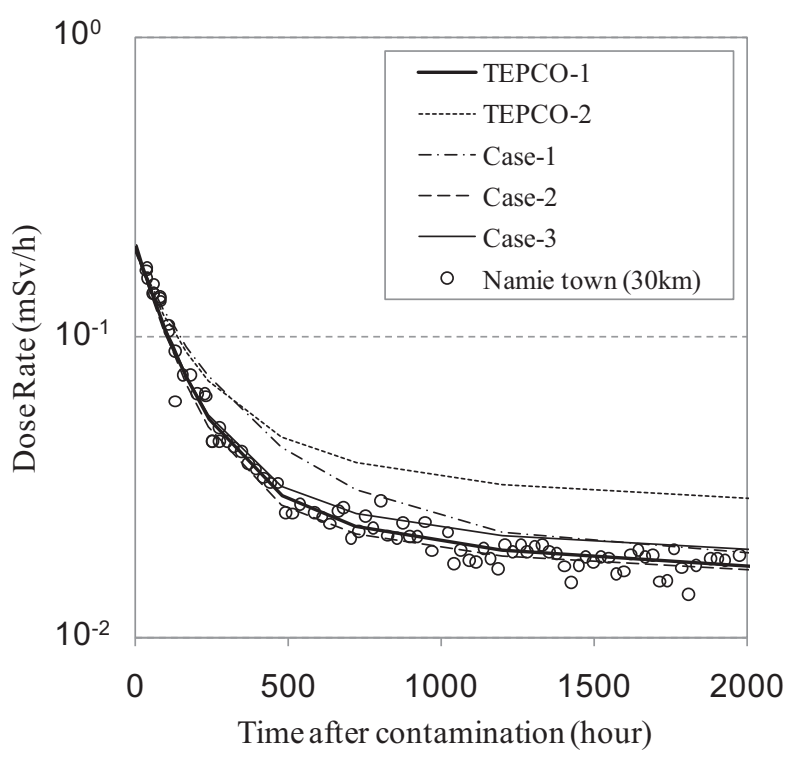

Fig. 2 Comparisons of the time variations of the assessed values based on the five accident scenarios with the measured data of a sampling point located in Namie town.

radionuclides into account. One should note that the magnitude of the initial values of the assessed dose rates for each accident scenario are normalized for the measured value of this sampling point at the initial time in accordance with the equation (4). Table 3 shows the compositions of representative radionuclides given by the ratio of the activity of each radionulide to ${ }^{137} \mathrm{Cs}$ at 00:00 on 16 March. These compositions were calculated using the results of source terms analysis by TEPCO and JNES and the initial inventory in the reactor core. The activities of the short-lived radionuclides such as ${ }^{132} \mathrm{I}$ and ${ }^{140} \mathrm{La}$ were derived from those of parent nuclide assuming radioactive equilibriums.

\begin{tabular}{|c|c|c|c|c|c|c|c|}
\hline \multirow{2}{*}{ Radionuclide } & \multirow{2}{*}{ Half-life } & \multirow{2}{*}{$\begin{array}{l}\text { Radionuclide } \\
\text { group }\end{array}$} & \multicolumn{5}{|c|}{ Accident scenario } \\
\hline & & & TEPCO-1 & TEPCO-2 & Case-1 & Case-2 & Case-3 \\
\hline${ }^{131} \mathrm{I}$ & $8.05 \mathrm{~d}$ & 1 & 7.55 & 7.81 & 19.1 & 6.94 & 7.11 \\
\hline${ }^{132} \mathrm{Te}$ & $3.25 \mathrm{~d}$ & 3 & 6.01 & 2.51 & 2.64 & 6.52 & 4.36 \\
\hline${ }^{134} \mathrm{Cs}$ & $2.05 \mathrm{y}$ & 2 & 1.11 & 1.11 & 1.11 & 1.11 & 1.11 \\
\hline${ }^{137} \mathrm{Cs}$ & $30.1 \mathrm{y}$ & 2 & 1.00 & 1.00 & 1.00 & 1.00 & 1.00 \\
\hline${ }^{140} \mathrm{Ba}$ & $12.8 \mathrm{~d}$ & 4 & 2.03 & 0.0633 & 10.1 & 0.108 & 0.145 \\
\hline
\end{tabular}

The time variations of the dose rates derived from the composition of radionuclides for the TEPCO-1, Case- 2 and Case-3 scenarios agreed with the measured ones during almost 500 hours after the contamination occurred. The time variations of these scenarios in this phase were strongly

Table 3 Preliminary estimated compositions of released activity normalized by ${ }^{137} \mathrm{Cs}$ for representative radionuclides on 16 -March

\section{Results and Discussion}

\section{Comparisons of the measured dose rates with the assessed values}

Figure 2 shows the results of comparisons of the time variations of the assessed dose rates with the measured ones at the sampling point located in Namie town at the distance $30 \mathrm{~km}$ from the NPP. The time variations of the dose rates shown in this figure are estimated based on the compositions of radionuclides for the five accident scenarios taking 44 influenced by the contributions of ${ }^{132} \mathrm{Te}$ and its progeny nuclide to the dose rates. On the other hand, the time variations of the dose rates calculated based on the compositions of radionuclides for the TEPCO-2 and Case-1 scenarios were not able to reproduce the time variation of the measured ones. The ratio of released activity for the TEPCO-2 and Case-1 scenario was characterized by low concentrations of the released activity of ${ }^{132} \mathrm{Te}$ into the atmosphere, which is less than a half compared with the 
others. This result indicates that the contributions of short-lived radionuclides such as ${ }^{132} \mathrm{Te}$ and its progeny nuclide to the dose rate are necessary to describe the time variation of the dose rate during the early phase after the deposition.

Figure 3 shows the results of comparisons of the time variations of the measured dose rates with the assessed ones which were derived from the composition of radionuclides based on the TEPCO-1 scenario. The time variations of the assessed values were in good agreement with the measured ones. Consequently, it was found that the model used in the present study was validated for assessing the time variations of the dose rates in the northwest area from the NPP. In addition, the time variations of the dose rates had no significant difference among the sampling points in the northwest areas, because of applying the composition for the TEPCO-1 scenario in common to all the sampling points.

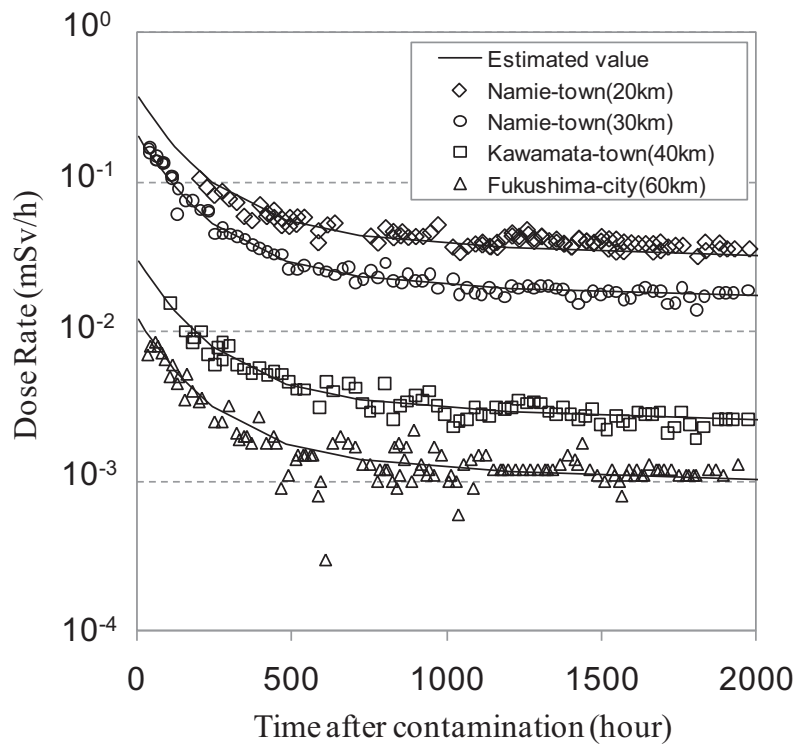

Fig. 3 Comparisons of the time variations of the assessed values based on TEPCO-1 scenario with the measured data at sampling points located in the northwest area from the NPP.

2. Contribution of each radionuclide to the cumulative dose

Figure 4 illustrates the contributions of individual radionuclides to the cumulative dose after the contamination occurred on 16 March, which were calculated for the TEPCO-1 scenario. The total contributions of ${ }^{131} \mathrm{I},{ }^{132} \mathrm{Te}$ and its progeny nuclide, ${ }^{132} \mathrm{I}$, in 10 days and a month were approximately $70 \%$ and $50 \%$, respectively. It is apparent that the contribution of these short-lived radionuclides is dominant in the early phase after the accident. Following decay of the short-lived radionuclides, ${ }^{134} \mathrm{Cs}$ and ${ }^{137} \mathrm{Cs}$ become the dominant contributors to the cumulative dose. The contribution of radioactive cesium to the cumulative dose for the first year is above $80 \%$.

\section{Conclusions}

Doses from external exposure due to deposited radionuclides were assessed taking the contributions of

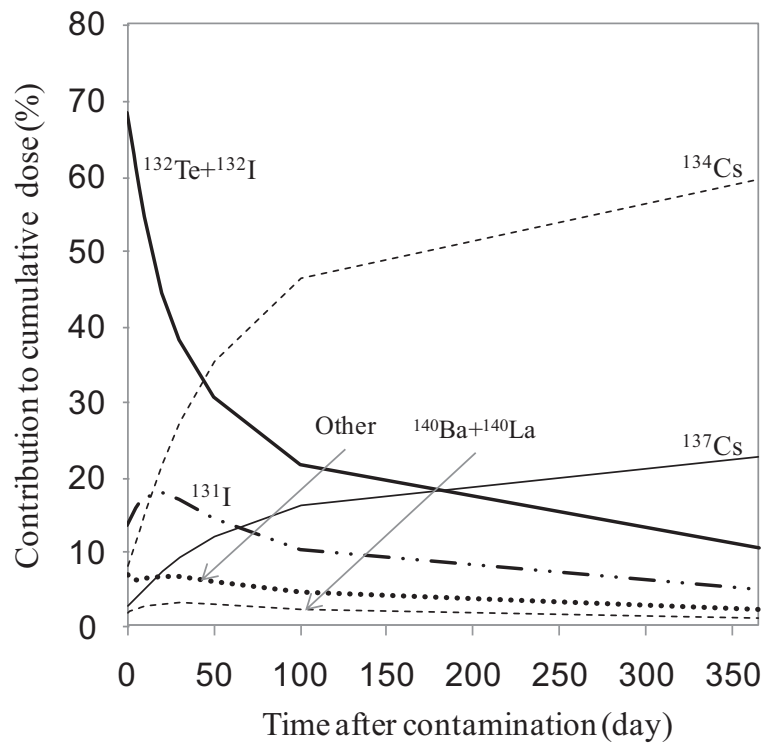

Fig. 4 Contributions of individual radionuclides to the cumulative doses derived from TEPCO-1 scenario during the first year after the contamination occurred.

short-lived radionuclides into account. The radionuclide compositions were obtained from the initial inventory in the reactor core evaluated and the released fractions published.

The time variations of the assessed dose rates were in good agreement with the measured ones. Consequently, it is found that the model used in the present study is useful for assessment of doses from external exposure due to deposited radionuclides. The results of the dose assessment indicate that the short-lived radionuclides such as ${ }^{132} \mathrm{Te}$ and ${ }^{132} \mathrm{I}$ were dominant contributors to the cumulative dose during the first month after the deposition. After the decay of the short-lived radionuclides, long-lived ${ }^{134} \mathrm{Cs}$ and ${ }^{137} \mathrm{Cs}$ were the dominant contributors to the cumulative dose.

These results are based on the current information on accident scenarios and environmental data. Further considerations will be needed to estimate doses taking the latest information into account. In particular, it should be noted that the impacts of the release from the reactors to the contamination of the environment cannot clearly distinguish between Unit 2 and Unit 4, and it is also difficult to determine the cause of the contamination based on the current information. In addition, assessment of doses from radioactive plumes in the early phase after the accident is an important issue to estimate doses from external exposure more accurately.

\section{References}

1) Matsumura, H., K. Saito, J. Ishioka and Y. Uwamino, "Diffusion of Radioactive Materials from Fukushima Daiichi Nuclear Power Station Obtained by Gamma-Ray Measurements on Expressways," Trans. At. Energy Soc. Japan, Vol. 10, No. 3, 152-162 (2011) (in Japanese).

2) The Ministry of Education, Culture, Sports, Science \& Technology in Japan.

3) http://www.mext.go.jp/english/

4) Prime minister of Japan and his Cabinet, Report of Japanese Government to the IAEA Ministerial Conference on Nuclear Safety (2011). 
Daiichi Nuclear Power Plant accident

5) ZZ ORIGEN2.2-UPJ, A complete package of ORIGEN2 libraries based on JENDL-3.2 and JENDL-3.3. http://www.oecd-nea.org/tools/abstract/detail/NEA-1642/

6) Katakura, J., M. Kataoka, K. Suyama, T. Jin and S. Ohki, “A set of ORIGEN2 Cross Section Libraries Based on JENDL-3.3 Library: ORLIBJ33," JAERI-Data/Code 2004-015 (2004).

7) K. Shibata, T. Kawano, T. Nakagawa, O. Iwamoto, J. Katakura, T. Fukahori, S. Chiba, A. Hasegawa, T. Murata, H. Matsunobu,

8) T. Ohsawa, Y. Nakajima, T. Yoshida, A. Zukeran, M. Kawai, M Baba, M. Ishikawa, T. Asami, T. Watanabe, Y. Watanabe, M. Igashira, N. Yamamuro, H. Kitazawa, N. Yamano and H. Takano: "Japanese Evaluated Nuclear Data Library Version 3 Revision-3: JENDL-3.3," J. Nucl. Sci. Technol. 39, 1125 (2002).
9) Katakura, J., and H. Yanagisawa, "Photon and decay data libraries for ORIGEN2 code based on JENDL FP decay data file 2000,"JAERI-Data/Code 2002-021 (2002).

10) ICRP, "Conversion coefficients for use in Radiological Protection against External Radiation," ICRP Publication 74, Ann. ICRP, Vol. 26, Issue 3-4 (1996).

11) Nuclear Safety Commission of Japan. The Emergency Preparedness Guidelines, "Emergency Preparedness of Nuclear Installations,” (2010).

12) EPA, "External Exposure to Radionuclides in air, water, and soil," Federal Guidance Report No.12 (1993).

13) Gale H.J., D.L.O. Humphreys and E.M.R. Fisher, "Weathering of Caesium-137 in Soil," Nature, No. 4916, 257-261 (1964). 